\title{
An Object Oriented Approach to Improve the Precision of Learning Object Retrieval in a Self Learning Environment
}

\author{
V. R. Raghuveer and B. K. Tripathy \\ VIT University, Vellore, Tamilnadu, India
}

\author{
vrraghuveer@vit.ac.in tripathybk@vit.ac.in
}

\begin{abstract}
With the advancements in the WWW and ICT, the e-learning domain has developed very fast. Even many educational institutions these days have shifted their focus towards the e-learning and mobile learning environments. However, from the quality of learning point of view, which is measured in terms of "active learning" taking place, the e-learning environment lags behind the traditional classroom based learning. One of the reasons for that is the availability of large volumes of static and unorganized contents over the e-learning environment which makes it difficult for learners to precisely identify the contents matching with their requirements. With the modern day e-learning environments providing the digital contents to their learners in the form of Learning Objects (LOs), creation of such LOs by proper composition along with meaningful metadata will help the learners to retrieve them precisely. The focus of this work is to address the issues related to imparting active learning over an e-learning environment through LOs. This paper proposes a new method to compose, share, reuse, and manage objects based on the principles of the Object Oriented Paradigm (OOP). The Learning Object Composition and Presentation System (LOCPS) developed as a part of this work has shown better results in precisely retrieving the objects matching with the learner requirements.
\end{abstract}

Keywords: Learning Objects, LO, Learning Object Granularity, Reusable Learning Objects, elearning, Learning Object Presentation, Learning Content Catalog

\section{Introduction}

E-learning originated from Computer Based Learning (CBL) where learning content in different forms like text, image, audio, and video were embedded into optical disks and given to the learners. With the evolution of web technologies, the content publishing has taken the shape of ebooks, online content pages (HTML), etc. The rapidly growing Internet resources have facilitated effective learning and training (Friesen, 2001). When the educational institutions started to deliver e-learning courses, there was a need to manage the activities associated with that, such as

Material published as part of this publication, either on-line or in print, is copyrighted by the Informing Science Institute. Permission to make digital or paper copy of part or all of these works for personal or classroom use is granted without fee provided that the copies are not made or distributed for profit or commercial advantage AND that copies 1) bear this notice in full and 2) give the full citation on the first page. It is permissible to abstract these works so long as credit is given. To copy in all other cases or to republish or to post on a server or to redistribute to lists requires specific permission and payment of a fee. Contact Publisher@InformingScience.org to request redistribution permission. user registration, content creation, content management, and evaluation (Dalsgaard, 2006; Rubin, Fernandes, Avgerinou, \& Moore, 2010). While the management activities were taken care of by the Learning Management Systems (LMSs), the learning contents were presented in the form of e-books and web documents. The changing learner requirements have stressed the need for 
new methods of content creation in order to achieve reusability. This resulted in the development of the Learning Content Management System (LCMS) which manages learning content in the form of small reusable chunks of digital information called learning objects (LOs) (Brennan, Funke, \& Anderson, 2001). Even though LMS and LCMS being two different systems, they still have a bit of each other's functionality in them (Jurubescu, 2008).

With the advent of LOs, more and more digital contents in the form of static files (HTML, PDF, documents) were used in e-learning environments. These files, at times, were large and granular in size and composed of different formats (text, image, audio, video, animation, etc.,) of contents together. The static nature of the contents composed inside these objects has prevented them from being reused flexibly. Moreover, the large granular objects were attributed partially with the metadata of few of its composing elements which the author feels important. These limitations burdened the learners by forcing them to spend more time to refine the search results. Also, the learner has to go through the retrieved object's content entirely in order to get the desired information. Thus the LO's granularity and composition become the important factors that greatly affects the effectiveness of learning over the e-learning environment. In order to ease the task of retrieving the precise contents to the learners and to reuse the LOs effectively, every object must be composed using the content elements that have well defined properties.

\section{Background Research on Learning Objects}

The IEEE Learning Technology Standards Committee defines a LO as "any entity, digital or nondigital, that may be used for learning, education or training" with additional information associated with it called Learning Object Metadata (LOM) (IEEE LOM, 2002). Considering the learning over the online environment, Wiley (2002) reframed this definition by characterizing the LO as "any digital resource that can be reused to support learning."

According to Metros \& Bennet (2002), LOs should not be confused with information objects that have no learning aim. McCormick (2003) added that the definition of a LO should include (either within or in a related documentation) some learning objectives and outcomes, assessments, and other instructional components, as well as the object itself.

Hodgins (2002) compares the LO to a piece of $\operatorname{Lego}^{\mathrm{TM}}$ (a kind of game played with toy building plastic bricks; www.lego.com) which can be combined with other pieces to assemble a larger object. The term "granularity" in the e-learning environment refers to the size of the digital content that could form a LO (Thompson, \& Yonekura, 2005). A granule may be of the size of a single text sentence or a course with multiple lines of text along with image, audio, video, etc. The small granular objects are more easily reused than the coarse granular ones. Coarse granular objects are easy to create, but reusing the parts of such objects involves more time and effort since repurposing the parts of the coarse granular objects has to be done by accessing its components and parsing them (Verbert, Jovanovic, Gasevic, \& Duval, 2005).

The LOM is the key to search and discover the objects stored inside the Learning Object Repository (LOR). The repository provides services like creating LOs, registering it, maintaining its metadata, and also search and discovery of objects, etc. (Najjar, Ternier, \& Duval, 2004). With the rise in the demand for learning content over the web, more and more repositories were created, which in turn necessitated the standardization of metadata (Duval, 2001). The IEEE LOM standard formulated nine different classes, viz., general, lifecycle, meta-metadata, technical, educational, rights, relation, annotation and classification, under which the metadata are categorized (IEEE LOM, 2002). Since the LOM standard does not strictly enforce the usage of all metadata categories along with the objects, there is only a partial usage of metadata categories. Ochoa, Klerkx, Vandeputte, and Duval (2011) highlight the common metadata categories that are frequently used along with objects. All together, the definitions of LO enforced that the object 
should be sharable, reusable, atomic, and objective based. It is these properties of LO that stressed the need for creating it in a standard way.

The growing number of LCMS however added another problem with respect to migration of objects created in one environment over the other. The standards like Sharable Content Object Reference Model (SCORM, 2004) and Instructional Management System's Common Cartridge (IMS, 2011) have addressed the problem by bundling the digital objects created along with the manifest file that contains information about how the object has to be used (Varlamis, \& Apostolakis, 2006). Such a bundle is unpacked in the target environment and the LOs are used based on the information available in the manifest file.

\section{Existing Methods for Learning Content Creation}

The e-learning environments utilize the services of Learning Object Repositories and tools to create, store, discover, and deliver the objects to the learners. Some of the popular methods for creating content over the e-learning environments which were studied and analyzed as a part of this work are as follows.

The LOR of Multimedia Educational Resource for Learning and Online Teaching (MERLOT) offers learning materials that are organized under categories such as animation, open book, presentations, exercises, and quiz. MERLOT LOR supports content creation in formats like HTML, PDF, Adobe Flash, image, SCORM, and VRML. Some of the learning objects are even linked to the external web page of the content authors that organizes the entire contents as a collection of HTML files (Mowat, 2005). MERLOT also supports building and hosting custom web pages with the help of a web page building tool called content builder that enables the authors to create HTML pages for e-portfolios, online course, pedagogy analysis, presentation, and tutorial (Swift, n.d). The contents created with content builder can be converted into the IMS CC format such that it could be used across the LMSs that support the format.

The National Learning Network (NLN) materials repository has a collection of learning materials hosted by Learning Skills and Improvement Service (LSIS). This repository supports creating bite sized objects that cater to the specific learning requirements of the learner. These materials are grouped under two major categories, namely, schools and other sectors, with each category having the objects under different levels like L1, L2, and L3 (Iqbal, 2009). Every object has a tutor guide that contains the entire learning content inside a document file.

Blackboard (2008) LMS, with its Blackboard Drive technology, organizes files with different content formats under a central repository from where they can be used for creating the object. This central repository provides a pool of resources that can be readily used by the authors to compose new objects.

In some learning environments, the LOs are created as HTML files and presented to the learners as a collection of freely expandable, interlinked web pages called wikis (Leuf \& Cunningham, 2001). Educational wikis present the content collection to the learners in the form of a hierarchy of hyperlinks to enable easy navigation. Wiki differs from a normal web page by supporting the edit option that allows contents to be composed in collaboration. The supplementary wiki created for the Mechanics course at MIT University by the Research in Learning, Assessing and Tutor Effectively (RELATE) group, helps the learners to use the learning materials more easily and effectively than a traditional e-book (RELATE, 2011).

Ed Morris (2005) in his work framed the LO as a class based on the object oriented software engineering approach with each class having four parts, namely, pre-knowledge questions, the learning material (content), self-evaluation questions and metadata. Moreover, the learning objects are created based on the class as atomic units, then grouped together and presented to the 
students in the form of a 45 minutes lecture. These atomic elements are in the form of text, image, etc., or a combination of them or even an HTML web page. The content part of such objects is decided by the teacher based on their student's requirements.

The importance of creating fine granular objects and its impact on the learners of e-learning environments was pointed out in the work of Holzinger, Smolle, and Reibnegger (2006). This work showcases a way of creating learning objects as classes using the object-oriented principles. Each learning concept was created as a class that takes appropriate inputs from the user through interaction and instantiates the LO dynamically.

The drawback with many of the existing systems is that they lack a well defined, time tested method for composing the LO. Even though a few of these systems adapt object oriented principles to create the LOs, the content part of such objects still remains as an unstructured file with large granular composition. The existing methods of content creation do not stress the importance of categorizing the elements composed inside an object. Also, the scalability of the contents inside these objects greatly affects the object's quality because the existing systems allow extending these objects by directly adding contents into the object's file. This in turn results in large granular objects with improper categorization and attribution of its composing elements. So, when the learner makes use of such objects, they have to process the entire file and manually extract the contents they need.

\section{The Need for a New System}

Since the existing systems allow objects to be created in any file format, the contents inside most of the objects are static by nature. The various formats in which the contents are presented to the learners are given in Figure 1. These formats do not allow the existing content to be modified or allow for new content to be added dynamically.

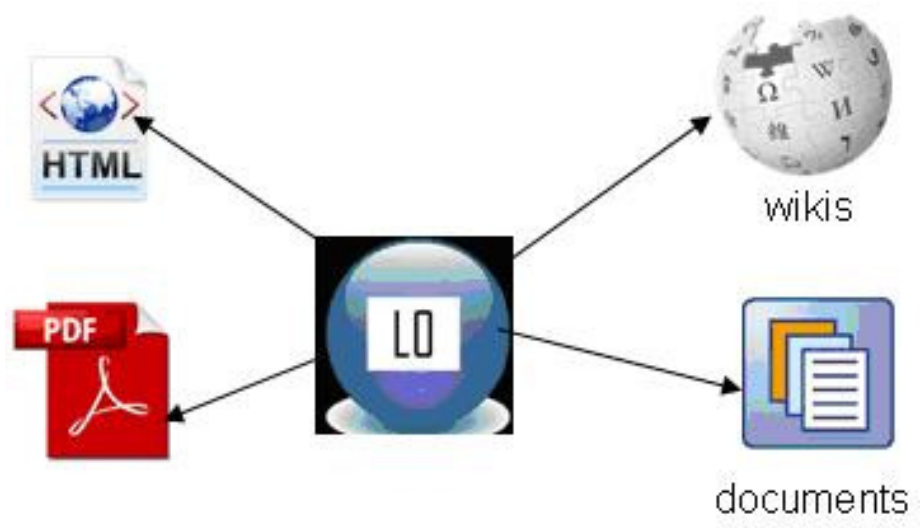

Figure1. File formats of traditional LOs

The drawbacks with the existing systems are due to the misunderstanding of the term LO and its definition by the content creators. In order to solve the problems with content presentation and structure, a new method of content creation has to be adapted such that the task of retrieving the precise content becomes easy.

The effectiveness of any information system is determined by two important factors, namely, precision and recall. So, the new system must be able to compose the objects in such a way that they can be retrieved back precisely. Also, the fraction of relevant documents retrieved (recall) must be more in order to give the learners a wide collection of contents (Raghavan, Bollmann, \& Jung, 1989). The Learning Object Composition and Presentation System (LOCPS) proposed in this 
work, improves the precision and recall of the retrieved results by creating fine granular objects and presenting them effectively to the learners.

\section{Object Oriented Approach for LO Creation}

In order to avoid the discrepancies that arise out of creating LOs by grouping the contents together in a single file, the LOCPS has adapted a novel method for creating the learning objects by strictly complying with the principles of OOP. In OOP, an object is defined as an instance of a class, whereas the class defines the set of properties each object must posses. This definition restricts the object and its nature based on the properties of the class (Booch, 1986). Also, the objects are by default categorized under the classes, thereby eliminating the problem of having irrelevant objects under a particular category. Moreover, OOP supports establishing relationships between classes using the concept of inheritance, in which detailed versions of an object can be created by utilizing the basic properties of its parent object. Since the data is given more preference in OOP, LOCPS objects created by following these principles stress mainly on the importance of data (metadata and the actual content) stored inside them.

\section{Classification, Type Separation and Categorization of Content}

LOCPS adapts a slight change over the existing definition of LOs, thereby "any digital entity can be considered as a learning object only when it satisfies a specific learning objective". For example, an image can be considered as a learning object only when it caters for a specific learning objective; otherwise, it is considered as a learning asset which can be used for the creation of learning objects. The two major categories of objects in LOCPS are the LO and Asset Object (AO). The asset objects are the basic building block of LOCPS as they are used primarily to create the LOs. A single AO can take part in multiple LOs by serving the specific objective in each learning object, thereby achieving polymorphism. Each AO contains one of the six categories of assets, namely, text, image, audio/video, animation, explanation, and problem/solution. The educational contents in the digital form collected from different sources are considered as assets. All the available digital assets can be categorized under one of the six types mentioned above. The assets necessary for evaluation, such as quiz and assessment, are not considered for implementation.

LOCPS, being an object oriented system, is capable of evolving based on the learner's requirements by supporting the creation of new asset categories as and when needed. The asset categories mentioned above are based on the type of contents usually presented to the learners over elearning environments. Apart from content type, the assets are also categorized based on the content category (definition, explanation, theorem, example, exercise, etc.), because the content category plays an important role in retrieving results in an e-learning environment.

A new AO is created with the help of an asset creation interface by making use of digital contents extracted from hard disks, optical media, or the web. The object thus created is marked as a temporary object and added to the Asset Object Repository (AOR). These temporary objects are then validated and made permanent so that they could be used readily at the time of creating the learning objects.

Figure 2 shows the schema of the LO, AO, and assets of the system. The LO class in Figure 2 is a container class that can accommodate any type of AO and other LOs as well. Since the traceability of these objects depends mainly on their metadata, the required metadata are obtained at the time of learning object creation. The attributes of these metadata are selected based on the survey results on the usage of metadata categories by Ochoa et al. (2011) and the specific requirements of learners of the system. 


\begin{tabular}{|c|c|c|c|c|}
\hline \multicolumn{2}{|c|}{ Leaming Object } & & & \multirow[b]{2}{*}{ Asset Object } \\
\hline \multirow{5}{*}{$\begin{array}{l}\text { LO.Id } \\
\text { Title } \\
\text { Description } \\
\text { Leaming Objective } \\
\text { Author } \\
\text { Pre-requisites } \\
\text { Aggregations } \\
\end{array}$} & \multirow{3}{*}{$\begin{array}{l}\text { Assets used } \\
\text { Content category } \\
\text { Keywords } \\
\text { Domain }\end{array}$} & & \multirow{6}{*}{ 1..* } & \\
\hline & & & & \multirow{3}{*}{$\begin{array}{l}\text { AO Id } \\
\text { Asset Type } \\
\text { Description } \\
\text { Keywords }\end{array}$} \\
\hline & & & & \\
\hline & \multirow[t]{2}{*}{ References } & & & \\
\hline & & & & \multirow{2}{*}{$\begin{array}{l}\text { +Create Asset Object } \\
\text { +Aggregate Asset Object } \\
\text { +View Asset Object }\end{array}$} \\
\hline $\begin{array}{l}\text { +Create Standalone } \\
\text { +Create Aggregated } \\
\text { +View Leaming Ob }\end{array}$ & $\begin{array}{l}\text { Dbject } \\
\text { Leaming Object } \\
\text { ect }\end{array}$ & & & \\
\hline
\end{tabular}

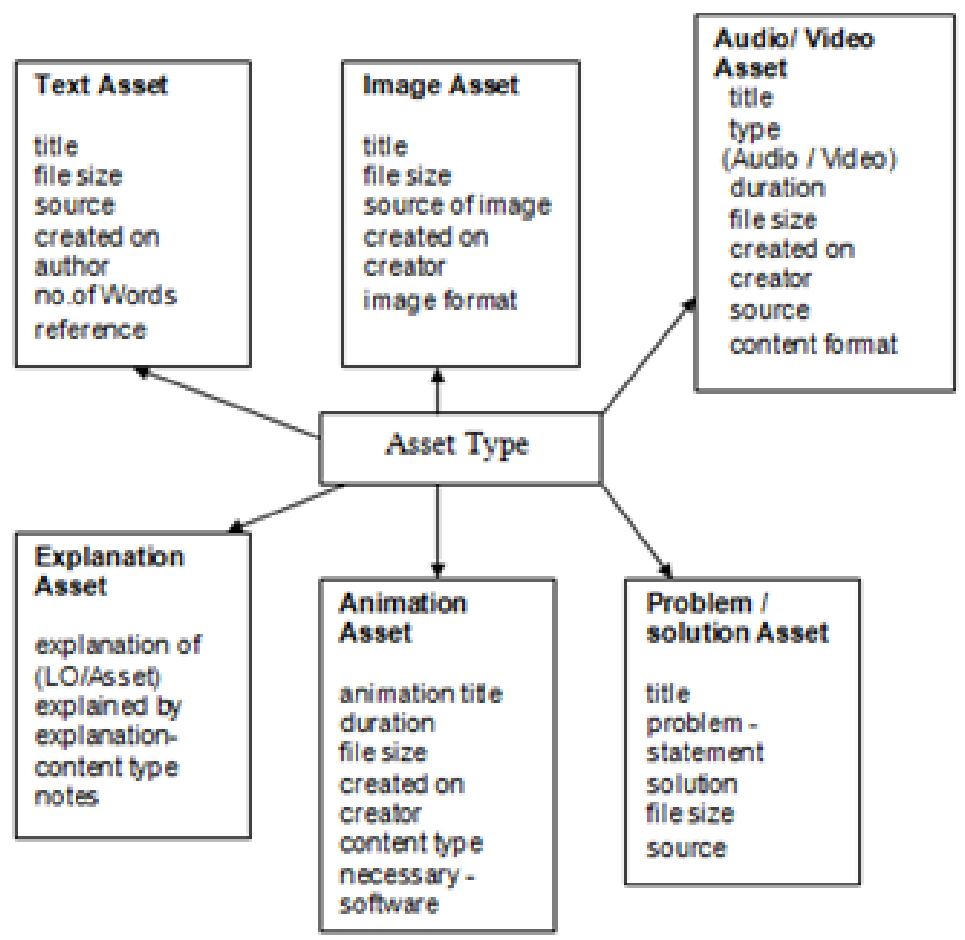

Figure 2. Attributes of LO, AO, and Assets of LOCPS

\section{Learning Object Content Assembly}

The content of the LO is created with the help of Learning Object Content Assembly Interface (LOCAI) by assembling the existing AOs available inside the repository. The metadata of learning objects thus created is the collection of metadata of its constituent elements. This allows the learner to search for the object based on its content type, category and composition.

The learning objective attribute represents the specific objective that the object is capable of catering. Each LOCPS object has an optional prerequisite field that links to the topics which are the prerequisite for the current object.

The architecture of LOCPS given in Figure 3 illustrates the three layers of the system, i.e., presentation layer, processing layer, and storage layer. The presentation layer interacts with the content authors and the learners through the web based interfaces. 


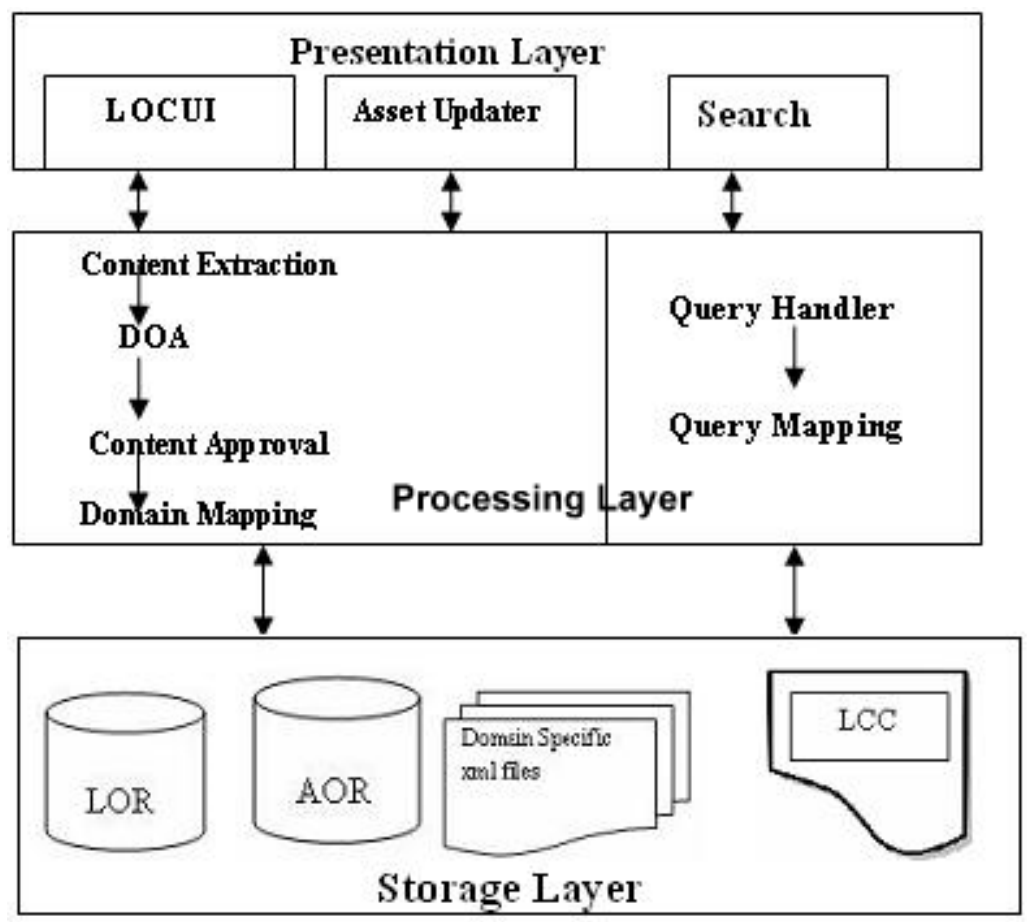

Figure 3. LOCPS Architecture

The processing layer handles the requests related to object creation, aggregation, and search. The learning objects created out of assets or by aggregating existing LOs are then approved by the reviewer and assigned a unique ID before they are stored permanently inside the repository. These objects are then mapped to appropriate domains by updating the information about the object in the domain specific XML files. Moreover, the objects are rated by domain experts and learners in different stages of object creation. Such ratings would add credibility to these objects, in turn enhancing its usability under appropriate domains. The query handler of the processing layer interacts with the learners to understand their requirements and formulates the query accordingly. The query thus formulated is then processed by the query mapper in order to match it with the domain names and domain specific keywords.

The data layer consists of Learning Object Repository (LOR), Asset Object Repository (AOR), domain specific XML files, and the Learning Content Catalog (LCC). The content catalog gives comprehensive information about the learning objects inside the repository and also allows the learners to search for the objects matching their requirements. Every time a new object is added to the repository, the catalog is updated with an entry that contains the attributes like keywords, domain, and type-wise inventory of objects. A sample LCC format in Table 1 gives the overall picture on the availability of objects to the learner.

\begin{tabular}{|l|l|l|l|l|l|l|l|}
\hline \multicolumn{7}{|c|}{ Table 1. A sample Learning Content Catalog format } \\
\hline Domain & Object Name & Tags & Text & Image & Audio/Video & Animation & Mixed \\
\hline C & Data types & $\begin{array}{l}\text { Data, data type, inte- } \\
\text { ger, float, double, } \\
\text { char }\end{array}$ & 2 & 2 & $1-$ Video & 0 & 1 \\
\hline Java & $\begin{array}{l}\text { Multi Thread- } \\
\text { ing }\end{array}$ & $\begin{array}{l}\text { Thread, parallel } \\
\text { processing }\end{array}$ & 1 & 1 & 1 - Audio & 1 & 1 \\
\hline
\end{tabular}




\section{Coarse Granular LO Creation with Dynamic Aggregation Model (DAM)}

LOCPS supports creating new objects by dynamically aggregating the existing learning objects inside the repository. Since the standalone objects created with LOCAI were of micro granular size, they can be flexibly used in creating new objects by aggregation and so they are called Flexible Learning Objects (FLOs). These objects are flexible in terms of usage under multiple learning modules without necessarily changing their content or structure. The goal of DAM is to aggregate such FLOs dynamically based on the learner's requirement. Figure 4 shows a sample concept design for creating an ALO named "Basic Pointer Concepts" under the Computer Programming domain.

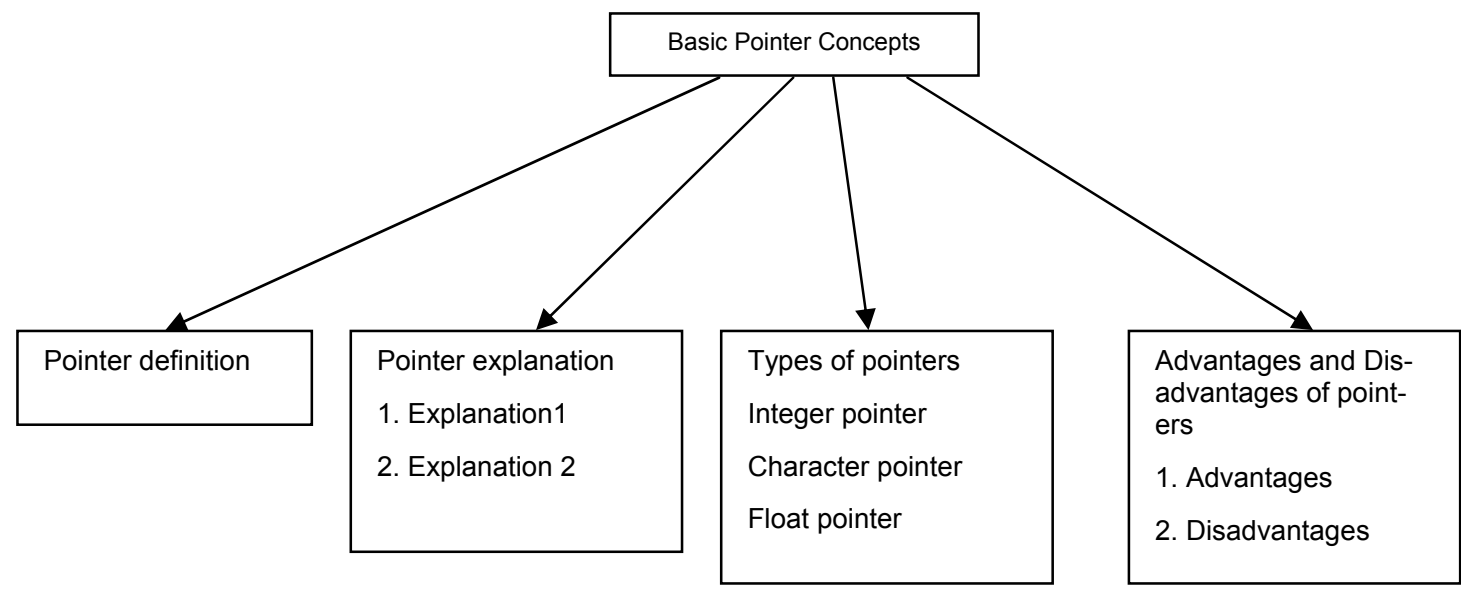

Figure 4. A typical concept design represented as a hierarchy of topics

A coarse granular object, based on the content design hierarchy of Figure 4, can be created in the traditional method by manually extracting the contents from various sources and assembling them together in a single file. Whereas, when the same object is created with Dynamic Object Aggregation Interface (DOAI) of DAM, the necessary objects are retrieved from the repository dynamically and aggregated based on the hierarchy of the concept design. Such an aggregated object is reused at a later stage either by modifying or without modifying its parts. The size of the coarse granular ALO created through the DOAI may range between topics of a chapter to a learning module made up of several chapters. Figure 5 shows the screenshot of DOAI for creating the ALO based on the concept design given in Figure 4. 


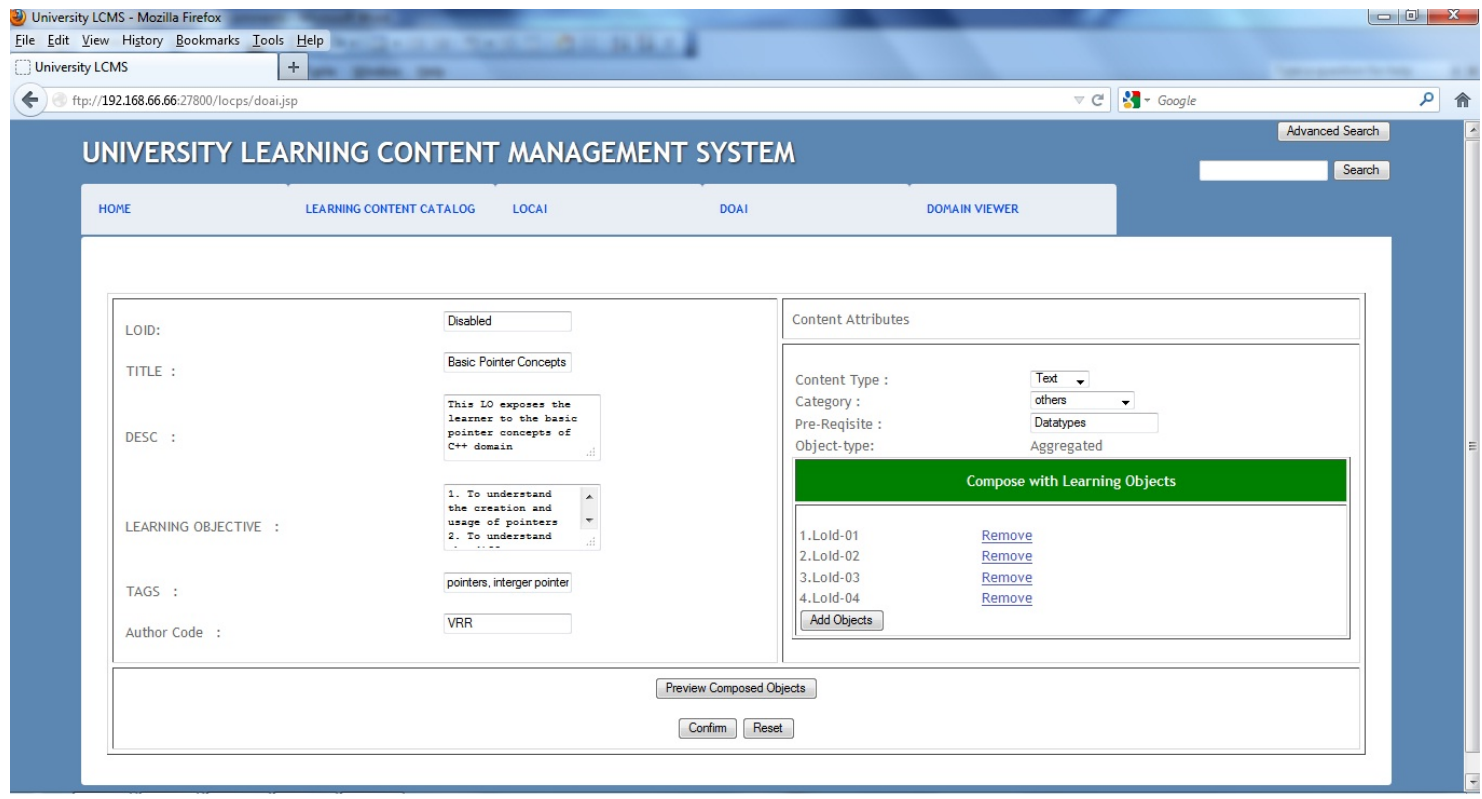

Figure 5. Screenshot of DOAI for dynamically aggregating the objects

The learning module thus created by aggregation is not as rigid as models were in the hardbound books or traditional e-books. New contents (LOs) can be added dynamically at different levels of the topic hierarchy thereby allowing the creation of flexible courses in order to cater for the learning needs of different category of learners. Yet another advantage of creating coarse granular objects with aggregation interface is that the constituent objects have their own metadata apart from having metadata for the entire ALO (Figure 6).

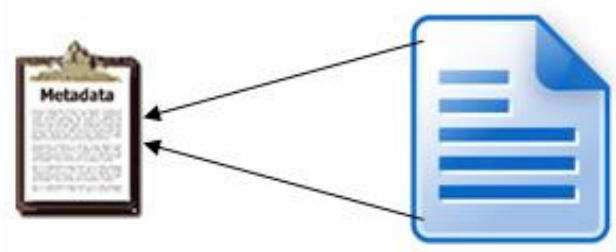

Traditional File Object and its metadata

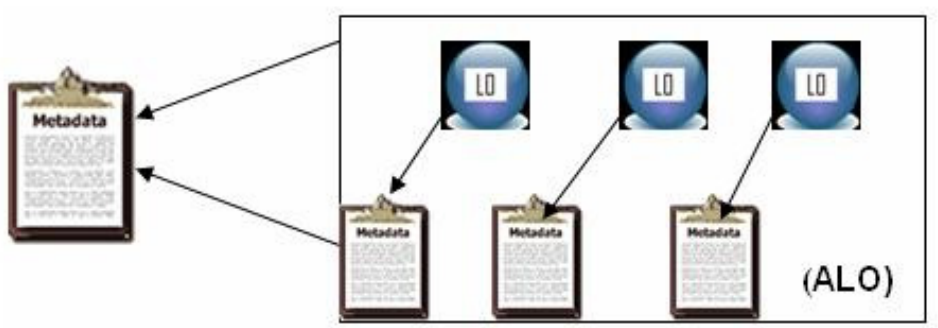

ALO with metadata for each LO

Figure 6. Traditional LOs vs. ALO of LOCPS

In contrast to this, a similar object created as a file has only one common metadata item for all the content elements inside the file. Since the metadata of a file is usually derived based on the frequent terms used inside it, the content elements of the file that lack in those terms cannot make its entry into the metadata information. Such a metadata file, which doesn't have extensive coverage over all the content elements of a file, may constrain the availability of the file and its content elements when searched by the learners. 


\section{Object Sequencing and Domain Mapping}

Sequencing of objects is an important aspect with respect to the presentation of learning objects. The AOs are usually sequenced inside a LO based on the order in which they were composed. In the case of aggregated objects, the constituent objects are either sequenced in the same order in which they were aggregated or based on the order insisted by the content author.

The learning objects created through LOCAI are then mapped to appropriate domains so that the object gains its credibility and, also, the availability of objects on domain specific searches is improved. Since this domain mapping is done explicitly by adding additional metadata to each object about the domains under which they are mapped to, there can be objects which are mapped to one or more domains and objects which are not mapped to any domain. In both cases, the object remains independent of the domain, as the additional domain specific metadata information can be removed anytime.

The domain mapping of objects updates the domain specific XML file with the information about the topics, sub topics, objects, and their associated metadata. These files are created once and contain entries of all subsequent objects mapped under that domain. Mapping of the objects under multiple domains helps to achieve polymorphism where the same object exists under different domains thus serving the purpose of the specific domain. Here, the objects themselves are not replicated; instead the information about the object alone is replicated under the XML files of appropriate domains. LOCPS allows mapping of objects anywhere under the categories and sub categories of a domain thereby organizing the objects hierarchically under the topics of a domain. Such a mapping would allow the learners to easily navigate through the domain hierarchy and find the appropriate object instead of searching for it with keywords.

\section{Object Search and Retrieval}

LOCPS supports searching for objects either by allowing the learner to select a particular domain and navigate through the domain hierarchy in order to find the appropriate objects or by making use of keywords to search the objects. When the learner uses the keyword for searching, the query handler picks the keyword and passes it to the query mapper. The query mapper in turn tries to match the query with the object's domain or tags or its title based on the information inside the content catalog. If the keyword matches with objects of multiple domains, then all the matching domains are presented before the learners so that they can select a particular domain for further processing. Once the results are refined based on the domain, the learner's interests in content category and content type is obtained, to refine the results further. The system interacts with the learner as and when there exists uncertainty in identifying the relevant object.

\section{Presenting the Objects}

The effectiveness of retrieving the precise objects is further improved by presenting them properly to the learners. Content presentation is an important aspect in which many of the LCMS lag behind. The contents presented to the learner must be properly organized. Most of the existing systems present the search results as a heap of files which the learner has to process manually in order to get the desired information. Since the learner's searches are mostly domain oriented, presenting the contents along with the hierarchy of topics under a domain will make the learner aware of the scope of the topics being covered in that domain. Such a domain based, hierarchical content presentation approach is used in LOCPS as the learners of the environment vary from novices to experts. 


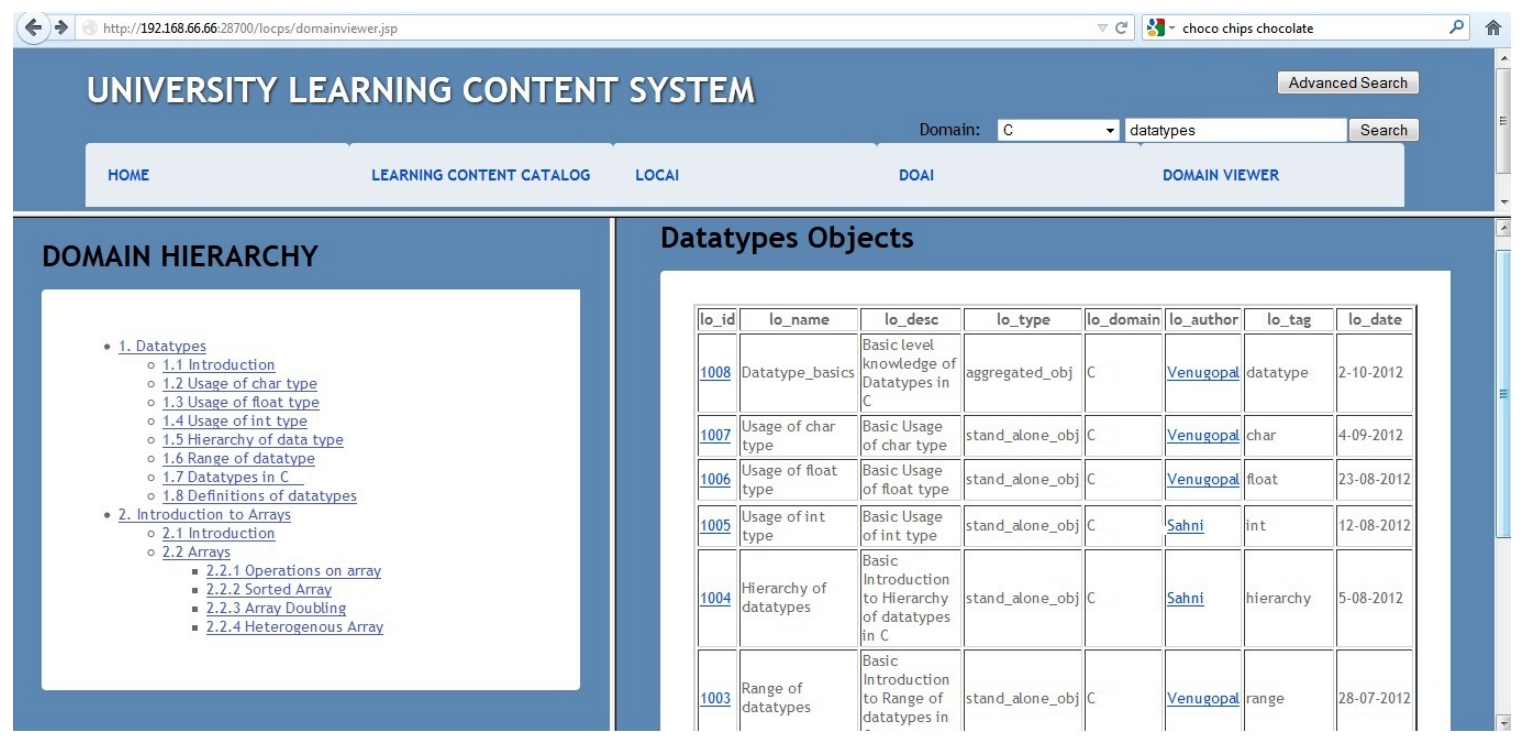

Figure 7. Screenshot of Domain Viewer interface

Figure 7 displays the contents retrieved for a specific search query keyword "datatypes" which was further refined with respect to the $\mathrm{C}$ domain. The search results are presented to the learners based on the $\mathrm{C}$ domain hierarchy information obtained from the XML file corresponding to that domain.

\section{Conforming to Standards}

LOCPS complies with SCORM standard in packaging the objects along with the manifest XML file such that it can be easily ported across the LMSs. The manifest file contains the metadata of the objects categorized under the domain hierarchy of a particular domain. The LOs in the form of small granular files are compressed and packaged along with the manifest file such that it can be unpacked and used inside any LMS environment that supports SCORM standard.

\section{Experimental Results}

The primary objective of LOCPS is to improve the precision and recall of the search results. Improving the precision will get the users the relevant results, whereas improving the recall gives the user the choice (author, content type, category, etc.) over the relevant contents. Usually, in an information retrieval environment, the precision and recall are calculated based on the values of four categories (represented as four quadrants Q1 through Q4 in Figure 8) under which the search results fall. They are (1) relevant and retrieved (TP-True Positive), (2) not relevant and not retrieved (TN-True Negative, results ignored as they were correctly identified as irrelevant), (3) not relevant and retrieved (FP - False Positive, irrelevant results that were wrongly identified as relevant and retrieved), and (4) relevant and not retrieved (FN - False Negative, relevant results wrongly identified as irrelevant and not retrieved) (Manning, Raghavan, \& Schütze, 2008). Out of these categories, the precision relies on TP and FP, since it is calculated as Precision $=\mathrm{TP} /$ $(\mathrm{TP}+\mathrm{FP})$. Whereas, Recall is calculated by using the formula Recall $=\mathrm{TP} /(\mathrm{TP}+\mathrm{FN})$. If TP is more and FP is less, then the system is more precise in retrieving the results for a given query. Likewise, if FN is reduced, then the number of relevant documents returned will increase thereby improving the recall of the system. 


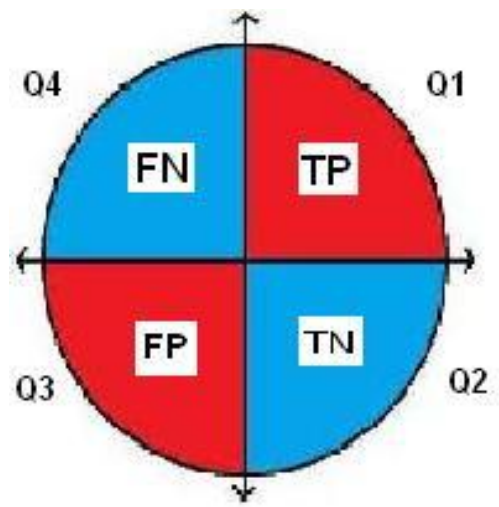

TP - Relevant and Retrieved

TN - Non Relevant and Not Retrieved

FP - Non Relevant and Retrieved

FN - Relevant and Not Retrieved

Figure 8. The four quadrants representing the category of results

A pilot experiment was conducted to test the performance of LOCPS objects against the HTML file based objects in terms of precision and recall. Since the coarse granular HTML files cannot be compared as such with the LOCPS objects, the content topics of the HTML file analogous to LOCPS objects are identified as "content elements" and then compared with LOCPS objects. Five subject topics (S1- datatypes, S2 - arrays, S3 - pointers, S4 - structures, and S5 - functions) relevant to the computer programming language domains like $\mathrm{C}$ and $\mathrm{C}++$ were considered for study. Table 2 lists the results of search made over LOCPS objects and traditional file system based objects by taking appropriate keywords under each topic.

\begin{tabular}{|c|c|c|c|c|c|c|c|c|}
\hline \multirow[t]{2}{*}{ Sl.no } & \multirow[t]{2}{*}{ Concepts } & \multicolumn{3}{|c|}{$\begin{array}{l}\text { LOCPS Objets re- } \\
\text { trieved }\end{array}$} & \multicolumn{4}{|c|}{$\begin{array}{l}\text { Total content elements among re- } \\
\text { trieved files }\end{array}$} \\
\hline & & $\mathbf{C}$ & $\mathrm{C}++$ & Others & $\begin{array}{l}\text { C } \\
\text { (files) }\end{array}$ & $\begin{array}{l}\text { Relevant } \\
\text { (C } \\
\text { domain) } \\
\text { content } \\
\text { elements }\end{array}$ & $\begin{array}{l}\text { C++ } \\
\text { (files) }\end{array}$ & $\begin{array}{l}\text { Others } \\
\text { (files) }\end{array}$ \\
\hline 1. & Data Types(S1) & 7 & 4 & 5 & $20(3)$ & 6 & $17(2)$ & $21(4)$ \\
\hline 2. & Arrays (S2) & 12 & 14 & 7 & $18(2)$ & 9 & $19(3)$ & $18(3)$ \\
\hline 3. & Pointers(S3) & 13 & 12 & 4 & $22(4)$ & 10 & $18(3)$ & $11(2)$ \\
\hline 4. & Structures(S4) & 10 & 6 & 2 & $20(3)$ & 9 & $28(3)$ & $7(1)$ \\
\hline 5. & Functions(S5) & 18 & 14 & 8 & $26(4)$ & 14 & $22(2)$ & $20(4)$ \\
\hline
\end{tabular}

\section{Result Analysis}

In our study, we have considered three domains, five subject topics, and a set of keywords associated with each of them (Appendix A and B). The number of keywords used for the pilot study was 152 and these were collected from the tags used for LOCPS objects and file objects (sample given in Appendix C). In the case of HTML file based objects these tags were automatically generated from the contents contained in it. Five sets of learners were chosen for searching the LOCPS and file based objects with the keywords of the five topics of study S1 to S5. Each set comprised of 3-5 learners based on the number of keywords falling under the particular search 
topic. The learners were made to search the system with the given keywords and the number of results returned was recorded along with the leaner's feedback on relevance among the retrieved results in each case. The LOCPS test search interface was made in such a way that it can retrieve both LOCPS and the file based LOs side by side when searched for a particular keyword. Since the precision of the search is determined based on the number of relevant results among those retrieved, it was decided to study the cases where maximum number of objects were retrieved under a particular topic and the results were tabulated in Table 2.

Table 2 lists only the five keywords that retrieved the maximum number of search results under the domains $\mathrm{C}, \mathrm{C}++$ and others. Here, the search with the keyword "Data Types" has retrieved a maximum of seven LOCPS objects of ' $\mathrm{C}$ ' domain and three matching files from file system based objects. These three files altogether possessed 20 content elements inside them, out of which only 6 were relevant (in all, out of twenty content elements only six possessed the keyword) to the query. Since the files retrieved also contained the content elements that were not relevant to the query, the learner was forced to process all the 20 content elements in order to extract the required content.

Figure 9 differentiates the LOCPS and traditional file based system in terms of relevancy of the retrieved results when searched with five different keywords (the data of " $\mathrm{C}$ domain" alone is considered in the chart). Also, it showcases the quantum of results to be processed by the learner in each case.

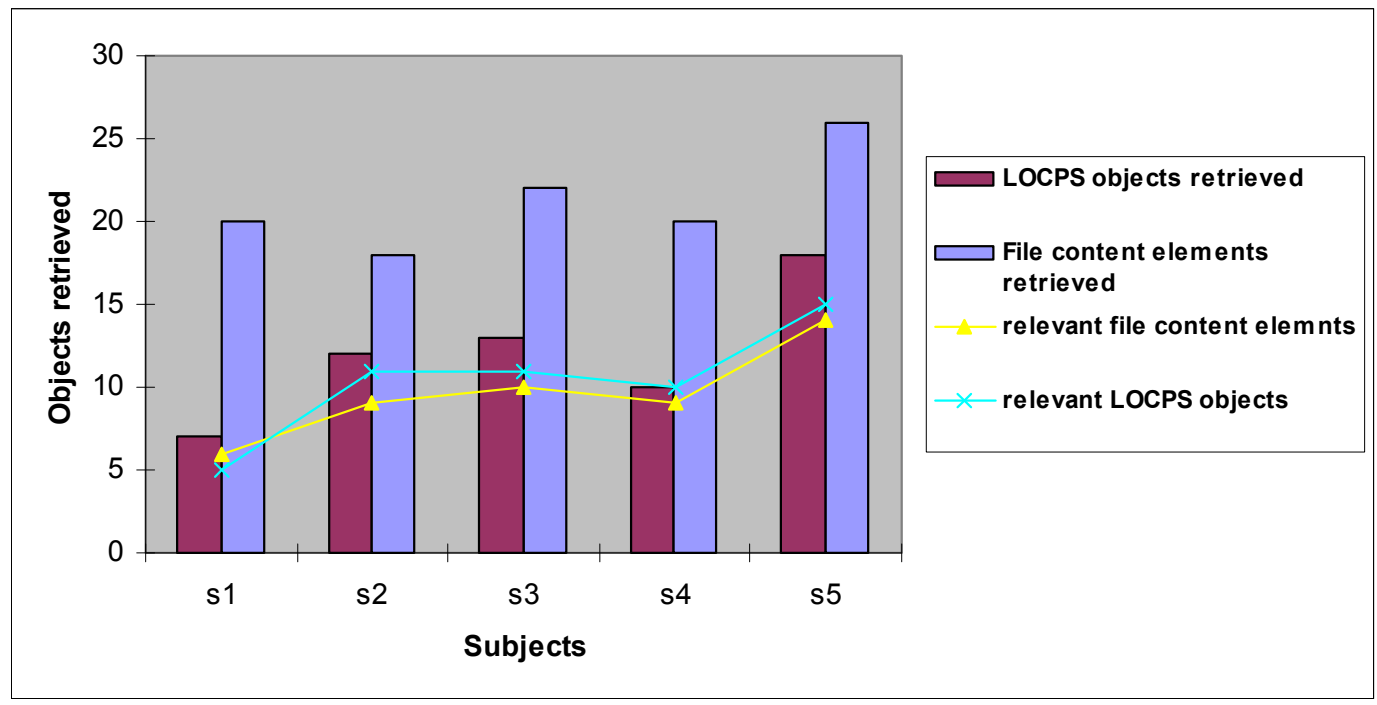

Figure 9. LOCPS VS Traditional File system

Table 3 lists the performance of LOCPS LOs against the traditional file content elements over the quadrants Q1, Q3 and Q4. Since the quadrants 1, 3, and 4 are only of interest, the data of quadrant 2 was ignored. 


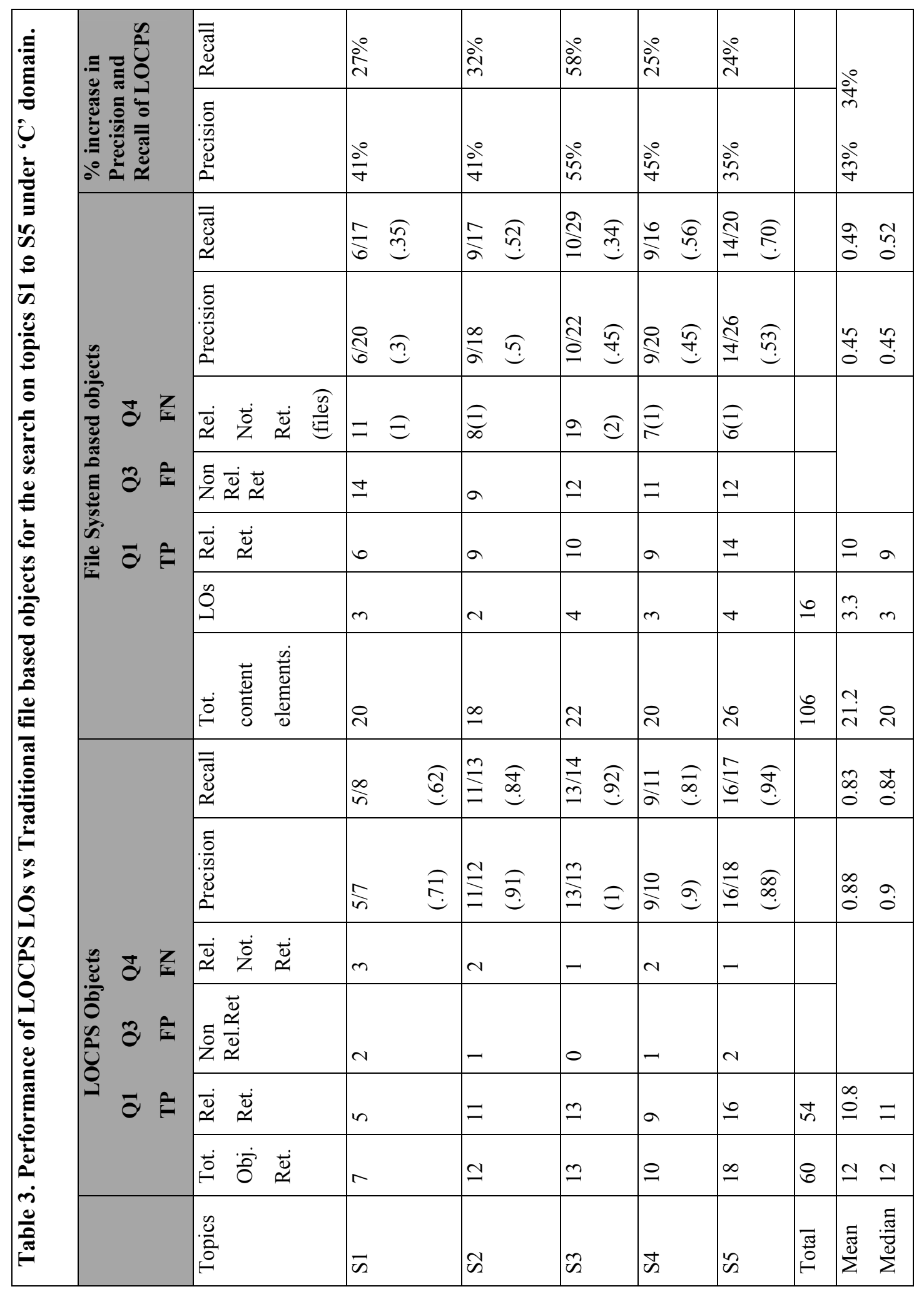


The precision and recall of the results retrieved using keyword S1 were calculated as follows,

$$
\begin{aligned}
& \text { Precision (TP/TP+FP): } \\
& \mathrm{P}_{\text {LOCPS }}=5 /(5+2)=0.71 \quad \mathrm{P}_{\text {Trad. }}=6 /(6+14)=0.3 . \\
& \text { Recall (TP/ TP+FN): } \\
& \mathrm{R}_{\mathrm{LOCPS}}=5 /(5+3)=0.625 \quad \mathrm{R}_{\text {Trad. }}=6 /(6+11)=0.35
\end{aligned}
$$

Similarly the precision and recall were computed for the results retrieved with keywords S2, S3, $\mathrm{S} 4$, and S5. In spite of the fact that the recall (results relevant to the query) of the system decreases by improving the precision, the results that are relevant to the learner will increase when the precision is improved. So, every time when the learner precisely identifies the do-

main/category/content type, the fraction of relevant (to the learner) results retrieved is improved. For an instance, the search with keyword "data types" has retrieved 16 objects from three domains that are relevant to the query keyword (Table 2). However, if the learner intends only for the results of $\mathrm{C}$ domain, then the fraction of relevant results out of the retrieved is only 7 out of 16. When the learner refines the results with respect to $\mathrm{C}$ domain, all the 7 results retrieved are relevant for the learner thus the recall is increased, but the recall with respect to the query is decreased (from 16 to 7 ).

In the case of recall of traditional file objects, the FN value is the number of relevant files not retrieved which in turn is the total number of content elements inside the relevant files that were not retrieved. Table 3 also shows that on an average, 10.8 out of 12 LOCPS LOs are relevant which is quite high in comparison to the results of traditional file system based objects where only 10 out of 21.2 content elements are relevant. The mean precision of LOCPS is $88 \%$ against $45 \%$ in case of traditional system. The mean recall (based on learner requirement) of LOCPS is $83 \%$ against $49 \%$ in case of traditional system. Also the percentage increase in precision is $43 \%$ and in recall is 34\%, which are almost 95\% improvement in precision and 69\% improvement in recall.

The $F_{1}$ score (Manning et al., 2008) calculated based on the mean values of precision and recall obtained from Table 3 are as follows:

$$
\begin{aligned}
& \mathrm{F}_{1} \text { Score }=2 * \text { Precision } * \text { Recall } /(\text { Precision }+ \text { Recall }) \\
& \mathrm{F}_{1 \text { LOCPS }}=2 * 0.88 * 0.83 /(0.88+0.83)=0.85 \\
& \mathrm{~F}_{1 \text { Trad.System }}=2 * 0.45 * 0.49 /(0.45+0.49)=0.47
\end{aligned}
$$

Overall, the above analysis establishes that the precision of LOCPS is comparatively better than the traditional file based objects. This is because of the fact that the LOCPS LOs are micro granular in nature, as well as they were all attributed with proper metadata. But, in the case of traditional file based objects, many content elements were packed together in a file and given a common metadata which lead to the retrieval of more non-relevant contents along with the relevant ones.

In Table 3, the Q3 value for S1 of LCOPS LOs is 3, because three relevant objects were not mapped to the $\mathrm{C}$ domain. So, when the search was refined with ' $\mathrm{C}$ ' domain, these results were ignored thereby reducing the recall of LOCPS. To improve the $\mathrm{R}_{\mathrm{LOCPS}}$, every LO should be mapped under appropriate domains. When similar mapping is done for file based objects, the recall will improve, but the precision goes down further as the FP contents (irrelevant contents inside each file) that gets retrieved along with each file will also increase.

Additionally, in LOCPS, the objects retrieved can be filtered further based on the content category and content type thereby more relevant contents can be provided to the learners. Whereas, in the case of traditional file based objects, such a filtering has to be done manually by the learner after going through all the content elements. 


\section{System Evaluation}

The LOCPS and traditional system were evaluated by the stake holders based on a set of parameters derived out of the definition of the term "Learning Object". The parameter categories listed in Appendix D have aided the evaluation of the systems on the following aspects, viz., the extent to which the LOs are composable (using existing LOs), reusable, sharable, and flexible. Also, the parameters identified have outlined the implicit requirement of any LO.

The system evaluation took place at different stages with appropriate parameters evaluated by the stake holders as given in Table 4. Questions were framed under each parameter (Appendix E) in such a way that their rating reflects the effectiveness of the learning content with respect to that parameter. These ratings were recorded on a 5 point scale (1-below average, 2-average, 3-good, 4- very good and 5- excellent).

\begin{tabular}{|l|l|l|l|}
\hline \multicolumn{4}{|c|}{ Table 4. Parameters and the stake holders considered for evaluation } \\
\hline Stake Holder & $\begin{array}{l}\text { No. Of } \\
\text { persons }\end{array}$ & Parameters Evaluated & Evaluation Stage \\
\hline $\begin{array}{l}\text { Content Au- } \\
\text { thors }\end{array}$ & 5 & $\begin{array}{l}\text { Ease of reusability, Dynamic content aggregation, } \\
\text { Flexible course creation }\end{array}$ & Content creation \\
\hline Learners & 20 & $\begin{array}{l}\text { Sharing content by parts, Learner customized con- } \\
\text { tent, Content evaluation, personalization. }\end{array}$ & Content Usage \\
\hline Teachers & 7 & $\begin{array}{l}\text { Ease of reusability, Dynamic content aggregation, } \\
\text { Flexible course creation, Improved Recall }\end{array}$ & Content Update \\
\hline
\end{tabular}

Figure 10 shows the results of evaluation of LOCPS against the traditional file based system. This shows that the traditional file based objects lags behind LOCPS LOs in the aspects that are considered to be important for today's e-learning environment.

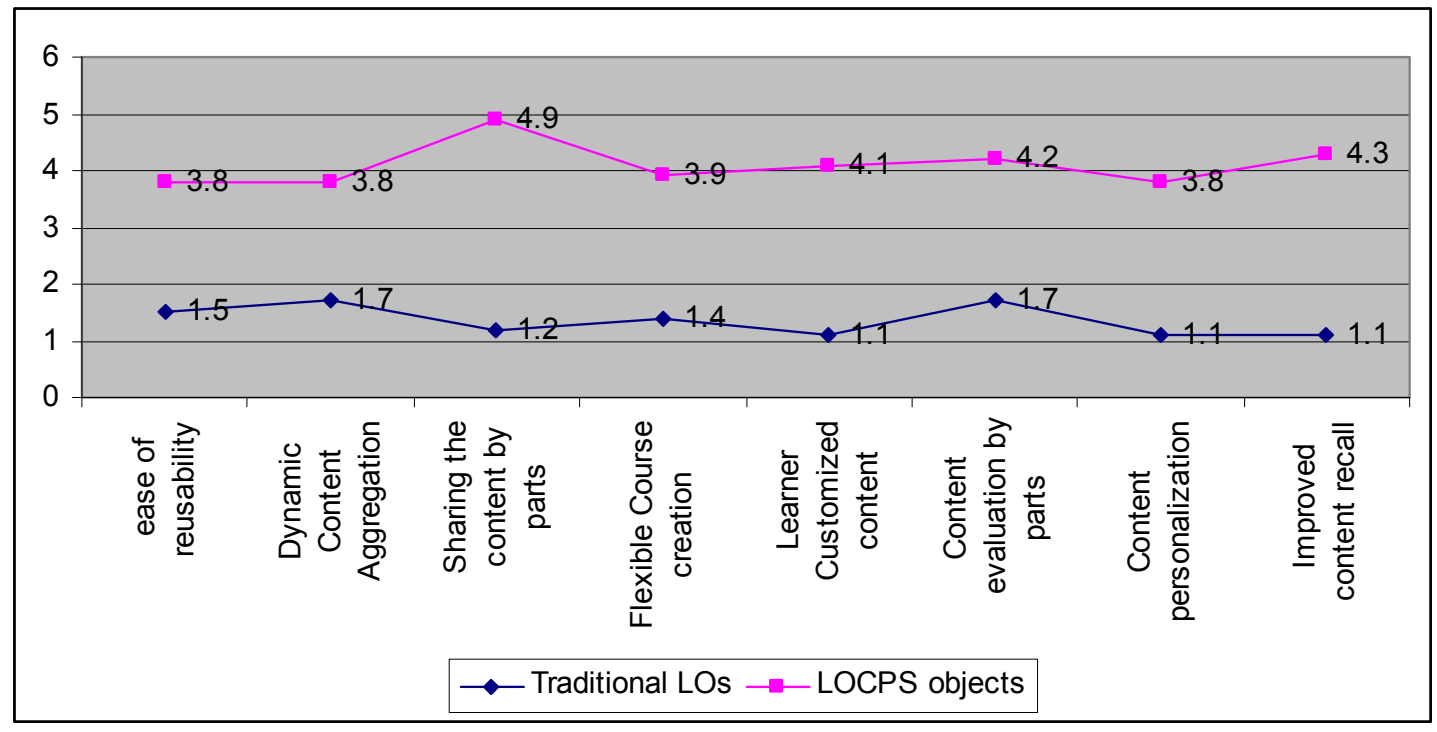

Figure 10. Evaluation of LOCPS

The collective mean and S.D values of ratings on LOCPS and traditional system given in Table 5 indicates that the mean value for LOCPS is much higher than that of the traditional system. Also, the higher S.D value for LOCPS than LO is due to its high superiority in one parametric esti- 
mated value, which is sharing content by parts. This is a positive sign only as this parameter has a significant role to play in e-learning than the others.

\begin{tabular}{|l|l|l|l|}
\hline \multicolumn{4}{|c|}{ Table 5. Mean, Median and SD of ratings of LOCPS and Tra- } \\
ditional File based system \\
\hline System & Mean & Median & St dev. \\
\hline LOCPS & 4.18 & 4.0 & 0.43 \\
\hline Traditional System & 1.3 & 1.3 & 0.25 \\
\hline
\end{tabular}

All these results have proved that LOCPS is more efficient than traditional file based system in all the parameters used for evaluation. The data sets used for evaluation were the learning contents created by content authors and teachers in the form of LOCPS LOs and HTML files. The only difficulty that the content authors faced with LOCPS was in terms of time and effort needed to create the contents from scratch by creating assets and LOs. This problem was addressed by making the system open ended, thereby allowing the stake holders to contribute AOs and LOs. The authenticity and quality of such contributed objects was upheld by peer reviewing the objects before they were approved and stored inside the repositories.

\section{Conclusion and Future Work}

While the traditional file based objects were composed with different forms (text, image, etc.) and categories of learning contents together, the objects of LOCPS classified the contents based on the domain, content category, and type, thereby improving the precision of retrieval. Since the LOCPS objects were created based on the principles of OOP, the problems associated with scalability of the system were addressed. The dynamic aggregation of objects has allowed the creation of custom courses that matches with the specific learning needs of the learner. The coarse granular contents created with ALO differed from the files of traditional system by summarizing the metadata of its objects contained in it. This in turn increased the chances of the content being retrieved during search. The query mapper of the system effectively handled the uncertainties in learner queries, in order to retrieve the precise contents for the learner. The LOs presented along with the domain hierarchy (through the domain viewer interface - Figure 7) has helped the learners to realize the coverage of the contents across the topics of the domain. The content catalog has provided comprehensive information about the objects inside the repository along with the inventory of their types. Altogether the LOCPS proved to be an efficient alternative to the traditional file system based objects.

With the existing metadata on content category, domain, and type supporting the effective retrieval and refinement of LOs, if the metadata dimensions are extended further to consider the information about the learning styles and learner preferences, then the learning objects can be retrieved according to the learner's expectations. This would benefit the learner by allowing them to decide the objects to be used by them, thereby making the contents more learner-centric. The future work is aimed at achieving dynamic adaptability of objects based on the learning styles and preferences of the learner.

\section{References}

Blackboard. (2008), Learning Management System. Retrieved from http://www.blackboard.com/Platforms/Learn/Products/Blackboard-Learn/Teaching-andLearning/Expanding-Learn/Content-management/Blackboard-Drive.aspx 
Booch, G. (1986). Object-oriented software development. IEEE Trans. Software Engineering, SE-12, 211221.

Brennan, M., Funke, S., \& Anderson, C. (2001). The learning content management system: A new elearning market segment emerges. IDC White Paper.

Dalsgaard, C. (2006). Social software: E-learning beyond learning management systems. European Journal of Open, Distance and E-learning. Retrieved from http://www.eurodl.org/materials/contrib/2006/Christian_Dalsgaard.htm

Duval, E. (2001). Metadata standards: What, who \& why. Journal of Universal Computer Science, 7(7), 591-601. Special Issue: I-Know 01 - International Conference on Knowledge Management.

Friesen, N. (2001). What are educational objects? Interactive Learning Environments, 9(3), 219-230.

Hodgins, W. H. (2002). The future of learning objects. Proceedings of e-Technologies in Engineering Education: Learning Outcomes Providing Future Possibilities, vol. 1, 76-82.

Holzinger, A., Smolle, J., \& Reibnegger, G. (2006). An object-oriented approach to manage e-learning content using learning objects. In A. Lazakidou (Ed.), Handbook of research on informatics in healthcare and biomedicine (pp. 89-98). Hershey, PA: Information Science Reference. doi:10.4018/978-1-59140982-3.ch012

IEEE LOM. (2002). Draft standard for learning object metadata. IEEE Learning Technology Standards Committee, IEEE 1484.12.1-2002. Retrieved from http://ltsc.ieee.org/wg12/files/LOM_1484_12_1_v1_Final_Draft.pdf

IMS. (2011). Common Cartridge version 1.2 Final Specification, October 2011. Retrieved from http://www.imsglobal.org/cc/ccv1p2/imscc profilev1p2-Overview.html

Iqbal, K. (2009). E-enabling offender learning and skills: NLN materials and offender learning. National Institute of Adult Continuing Education. Retrieved from http://shop.niace.org.uk/nln-materialsoffender.html

Jurubescu, T. (2008). Learning content management systems. Informatica Economica Journal, XII(4), 9194.

Leuf, B., \& Cunningham, W. (2001). The Wiki Way: Quick collaboration on the web. Boston: Addison Wesley. ISBN: 0-201-71499-X.

Manning, C. D., Raghavan, P., \& Schütze, H. (2008). Introduction to information retrieval (Vol. 1). Cambridge: Cambridge University Press.

McCormick, R. (2003). Keeping the pedagogy out of learning objects. Symposium Designing Virtual Learning Material, EARLI 10th Biennial Conference: Improving Learning, Fostering the Will to Learn, Padova, Italy, 26-30 August, 2003.

Metros, S. E., \& Bennet, K. (2002). Learning objects in higher education. Research Bulletin EDUCAUSE Center for Applied Research, November 1, 19.

Morris, E. (2005). Object oriented learning objects. Australasian Journal of Educational Technology, 21(1), 40-59. Retrieved from http://www.ascilite.org.au/ajet/ajet21/morris.html

Mowat, J. (2005, August 15). Faster, better, cheaper: Improve corporate e-learning content management with MERLOT. The e-Learning Developers'Journal.

Najjar, J., Ternier, S., \& Duval, E. (2004). Interoperability of learning object repositories: Complications and guidelines. IADIS International Journal on WWW/Internet, 2(1), 1-16.

Ochoa, X., Klerkx, J., Vandeputte, B., \& Duval, E. (2011). On the use of learning object metadata: The GLOBE experience. European Conference on Technology Enhanced Learning, pp. 271-284.

Raghavan, V., Bollmann, P., \& Jung, G. S. (1989). A critical investigation of recall and precision as measures of retrieval system performance. ACM Transactions on Information Systems, 7, 205-229. 
RELATE. (2011). REsearch in Learning, Assessing, and Tutoring Effectively. MIT. Retrieved from: https://wikis.mit.edu/confluence/display/RELATE/RELATE+MechanicsWIKI+Home

Rubin, B., Fernandes, R., Avgerinou, Maria D., \& Moore, J. (2010). The effect of learning management systems on student and faculty outcomes. The Internet and Higher Education, 13(1-2), 82-83.

SCORM. (2004). ADL SCORM, SCORM 2004 4th Edition Specification. Retrieved from: http://www.adlnet.org/scorm/index.cfm

Swift, C. (n.d). Effective uses of content builder tool. Retrieved from http://contentbuilder.merlot.org/toolkit/html/stitch.php?s=65391682894334

Thompson K., \& Yonekura, F. (2005). Practical guidelines for learning object granularity from one higher education setting. Interdisciplinary Journal of Knowledge and Learning Objects, 1, 163-179. Retrieved from http://www.ijello.org/Volume1/v1p163-179Thompson.pdf

Varlamis, I., \& Apostolakis, I. (2006). The present and future of standards for e-learning technologies. Interdisciplinary Journal of Knowledge and Learning Objects, 2, 59-76. Available at http://ijklo.org/Volume2/v2p059-076Varlamis.pdf

Verbert, K., Jovanovic, J., Gasevic, D., \& Duval, E. (2005). Repurposing learning object components. Lecture Notes in Computer Science (2005), 1169-1178.

Wiley, D. (Ed.). (2002).The instructional use of learning objects. Retrieved from: http://reusability.org/read/

\section{Appendix A}

Domain and the range of data considered for evaluating the system

\begin{tabular}{|l|l|}
\hline Domains & 3 \\
\hline Total files & 43 \\
\hline Total content elements & 106 \\
\hline Total LOCPS Objects & 136 \\
\hline No. of Keywords used for pilot study & 152 \\
\hline Total no. of keywords & 212 \\
\hline
\end{tabular}

\section{Appendix B}

\section{Data set used for analysis - Including all three domains (C, C++, Others)}

\begin{tabular}{|r|l|r|r|}
\hline \multicolumn{1}{|l|}{ Serial No. } & Concept Topic & LOCPS (Objects) & \multicolumn{2}{|l|}{ Traditional(Files) } \\
\hline 1 & Data Types & 16 & 9 \\
\hline 2 & Arrays & 33 & 8 \\
\hline 3 & Pointers & 29 & 9 \\
\hline 4 & Structures & 18 & 7 \\
\hline 5 & Functions & 40 & 10 \\
\hline & Total & $\mathbf{1 3 6}$ & $\mathbf{4 3}$ \\
\hline
\end{tabular}




\section{Appendix C \\ Sample keyword set used for the search on the topic "Data Types"}

\begin{tabular}{|l|l|l|l|}
\hline Domain & Topic & Keyword set used & LO Objects \\
\hline C & Data Types & $\begin{array}{l}\text { Datatypes, datatype range, primitive } \\
\text { datatype, ADT, derived datatype, inte- } \\
\text { ger, float, char, long, double, type cast- } \\
\text { ing, implicit casting, explicit casting, } \\
\text { hierarchy of datatypes. }\end{array}$ & $\begin{array}{l}\text { Datatype definition } \\
\text { Datapes in C } \\
\text { Datatypes and range } \\
\text { Hierarchy of datatypes } \\
\text { The Integer datatype } \\
\text { Float datatype } \\
\text { Character datatype }\end{array}$ \\
\hline
\end{tabular}

\section{Appendix D}

Parameters used for comparing LOCPS and traditional system

\begin{tabular}{|r|l|}
\hline \multicolumn{1}{|l|}{ Serial No. } & Parameter \\
\hline 1 & Ease of reusability \\
\hline 2 & Dynamic Content Aggregation \\
\hline 3 & Sharing the content by parts \\
\hline 4 & Flexible Course creation \\
\hline 5 & Learner Customized content \\
\hline 6 & Content evaluation by parts \\
\hline 7 & Content personalization \\
\hline 8 & Improved content recall \\
\hline
\end{tabular}




\section{Appendix E}

Questions used for evaluating appropriate parameters

\begin{tabular}{|c|c|c|}
\hline Serial No. & Question & Parameter Category \\
\hline 1 & Ease of content discovery & 1 \\
\hline 2 & Ease of content extraction & 1 \\
\hline 3 & Ease of content reuse & 1 \\
\hline 4 & Extracting the objects for dynamic composition & 2 \\
\hline 5 & Searching objects for dynamic composition & 2 \\
\hline 6 & Assembling a dynamic object and sequencing & 2 \\
\hline 7 & Need for extracting content to be shared & 3 \\
\hline 8 & Ease of sharing parts of the content & 3 \\
\hline 9 & Possibility for Implicit sharing & 3 \\
\hline 10 & Content extraction complexity for course creation & 4 \\
\hline 11 & Dynamic addition of contents to an existing course & 4 \\
\hline 12 & Dynamic creation of a course & 4 \\
\hline 13 & Content discovery based on requirements & 5 \\
\hline 14 & Content organization & 5 \\
\hline 15 & Customizing the delivery of contents & 5 \\
\hline 16 & Rating the entire content & 6 \\
\hline 17 & Rating the objects individually & 6 \\
\hline 18 & Effective usage of content based on part rating & 6 \\
\hline 19 & Presenting the contents based on learner preferences & 7 \\
\hline 20 & Matching parts of contents that matches learner preferences & 7 \\
\hline 21 & Giving the contents based on the needs of learners & 7 \\
\hline 22 & Extending the keyword used for search & 8 \\
\hline 23 & Mapping the keyword to domain of knowledge & 8 \\
\hline 24 & Use of domain Catalog to improve recall & 8 \\
\hline
\end{tabular}




\section{Biographies}

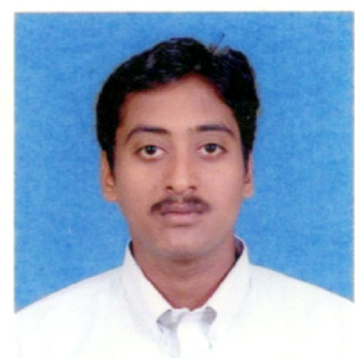

V. R. Raghuveer received his B.E degree in 2002 from Computer Science and Engineering department of Bharadhidasan University, India. He received his M.E degree in 2005 from Anna University, India. He is now pursuing his Ph.D at VIT University, in the field of information retrieval for e-learning.

Currently, he is working as an Assistant Professor in School of Computing Science and Engineering at VIT University, India. His research interests includes learning content creation, dynamic learner profiles, automated learning content generation and fuzzy-approaches for LO retrieval.

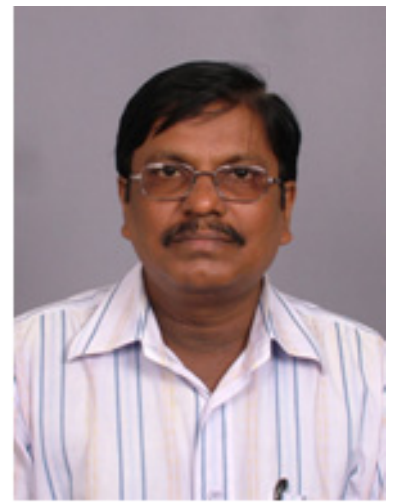

B. K Tripathy is a senior professor in the school of computing sciences and engineering, VIT University, at Vellore, India. He has published more than 170 technical papers in international journals/ proceedings of international conferences/ edited book chapters of reputed publications like Springer and guided 12 students for $\mathrm{PhD}$. so far. He is having more than 30 years of teaching experience. He is a member of international professional associations like IEEE, ACM, IRSS, CSI, IMS, OITS, OMS, IACSIT, IST, ACEEE, CSTA, and is a reviewer of around 30 international journals which include World Scientific, Springer and Science Direct publications. Also, he is in the editorial board of at least 12 international journals.

His current research interest includes Fuzzy sets and systems, Rough sets and knowledge engineering, Granular computing, e-learning content creation, data clustering, database anonymization, soft computing, remote labs scheduling, bag theory, list theory and social network analysis. 